\title{
Assessment of Knowledge Level of People Regarding Rain Water Harvesting
}

\author{
Anshul Bhutani* and Dr. Binoo Sehgal** \\ *Ph.D. Scholar, Deptt. of Family Resource Management \\ ** Professor, Deptt. of Family Resource Management \\ College of Home Science, CCSHAU, Hisar - 125004 (Haryana)
}

\begin{abstract}
Water resources are limited and are becoming a scarce commodity everyday due to ever-increasing demand in proportion to the rapidly increasing population. In the face of increasing scarcity of water resources, there is a need for communities to undertake audits of their current rainwater harvesting potential as a practical and promising alternative solution for water shortage. For conservation of water resources, rain-water harvesting from roof-top catchments should be done. In this paper, structural components and advantages of rain water harvesting from roof-top catchments have been discussed to increase the existing level of knowledge of the people. For this study, four villages 4 villages i.e. Chowdhariwas, Balawas, Balsamand and Paniharchak were selected from Hisar district of Haryana state. A sample of thirty women respondents were taken randomly from a cluster of these villages. Forty-three percent of the respondents belonged to middle age group (25-50 years), were housewives (60.00\%) and family occupationwas farming (76.67\%). Pre and post-exposure knowledge of respondents was found out and overall, gain in knowledge regarding rainwater harvesting was found to be high. Majority of the respondents were now ready to adopt the technology in their farm as well as in their homes after knowing the benefits of the technology.
\end{abstract}

\section{Introduction}

Water is essential for life and used in many different ways. It is also a part of the larger ecosystem in which the reproduction of the bio diversity depends. Fresh water scarcity is not limited to the arid climate regions only, but in areas with good supply the access of safe water is becoming critical problem. The significance of fresh water is well recognized and documented. Water is a prerequisite for life and without it there will be no living thing. The easy access to water remained a serious issue in both urban and rural areas in developing as well as developed countries (Tripathi and Pandey, 2005). Particularly, its importance is further enhanced in rural areas where access to water is difficult, expensive and tiresome (Kumar, 2009). Rain water harvesting is the concept, which includes a holistic approach to develop, augment, and protect and conserve water resources. This concept is to be envisaged and practiced in order to ensure the sustainability and to provide scope for further development of growing demand of population. Water is typically available for limited hours a day in most Indian cities. The situation is even worse in summer when water is available only for a few minutes, sometimes not at all to. In Delhi approximately 13 per cent households do not receive water every day and in Rajkot (Gujarat) water availability in April 2000 was only for 30 minutes every alternate day (Zerah, 2000).

Surface water sources fail to meet the rising demands of water supply in rural and urban areas. This precarious situation needs to be rectified by immediately recharging the depleted aquifers. Hence, the need for implementation of measures to ensure that rain falling over a region is tapped as fully as possible through water harvesting and storing it for direct use. Based on the above rationale, the present study was undertaken to study the knowledge level of respondents regarding rain water harvesting.

\section{Methodology}

Locale of the Study: The present study was conducted in Hisar district of Haryana state. Four villages i.e. Chowdhariwas, Balawas, Balsamand and Paniharchak were purposively selected because these are located in dry land area and rain water harvesting technology has already been adopted by some of the families. A sample of thirty women respondents was taken randomly from a cluster of these villages.

Variables and Their Measurements: Aninterviewschedule was developed to study independent variables like age, education, type and size of family, caste, income, occupation etc. A knowledge inventory on various aspects of rainwater harvesting was prepared to assess the knowledge of the respondents.

Knowledge Gain: Knowledge gain was operationalized as the amount of information acquired by the respondent as a result of the training. The inventory was subjected to respondent before and after the training. Questions were asked in Yes/No and scores were assigned as 2 and 1 respectively. 
Analysis of Data: The qualitative data were quantified according to the laid down standards and tabulated to draw meaningful inferences. Statistical parameters like frequency, percentage and mean score were applied to assess and interpret data. Paired' $t$ ' - test was applied to measure the significance of gain in knowledge at pre and post-exposure stage.

\section{Results And Discussion}

Results achieved have been presented in the following sub-heads:

Socio-personal Profile: Data in Table 1 revealed that forty-three percent of therespondents belonged to middle age group (25-50 years) and were illiterate (26.67\%).Majorityof respondents were married (70.00\%),belonged to joint family $(73.33 \%)$, and hada family size of 5-7 members $(53.33 \%)$.

Economic Profile of the Respondents: Economic profile is presented in Table 2.Data in table indicate that majority of respondentswere housewives $(60.00 \%)$ and family occupationwas farming (76.67\%). Monthly family income was betweenRs. 20,000- to 30,000 for maximum number ofrespondents $(53.33 \%)$ and majority of the respondents $(60.00 \%)$ were having 5-7 hectares of land.

Table1: Socio-personal profile of the respondents

$\mathbf{n}=\mathbf{3 0}$

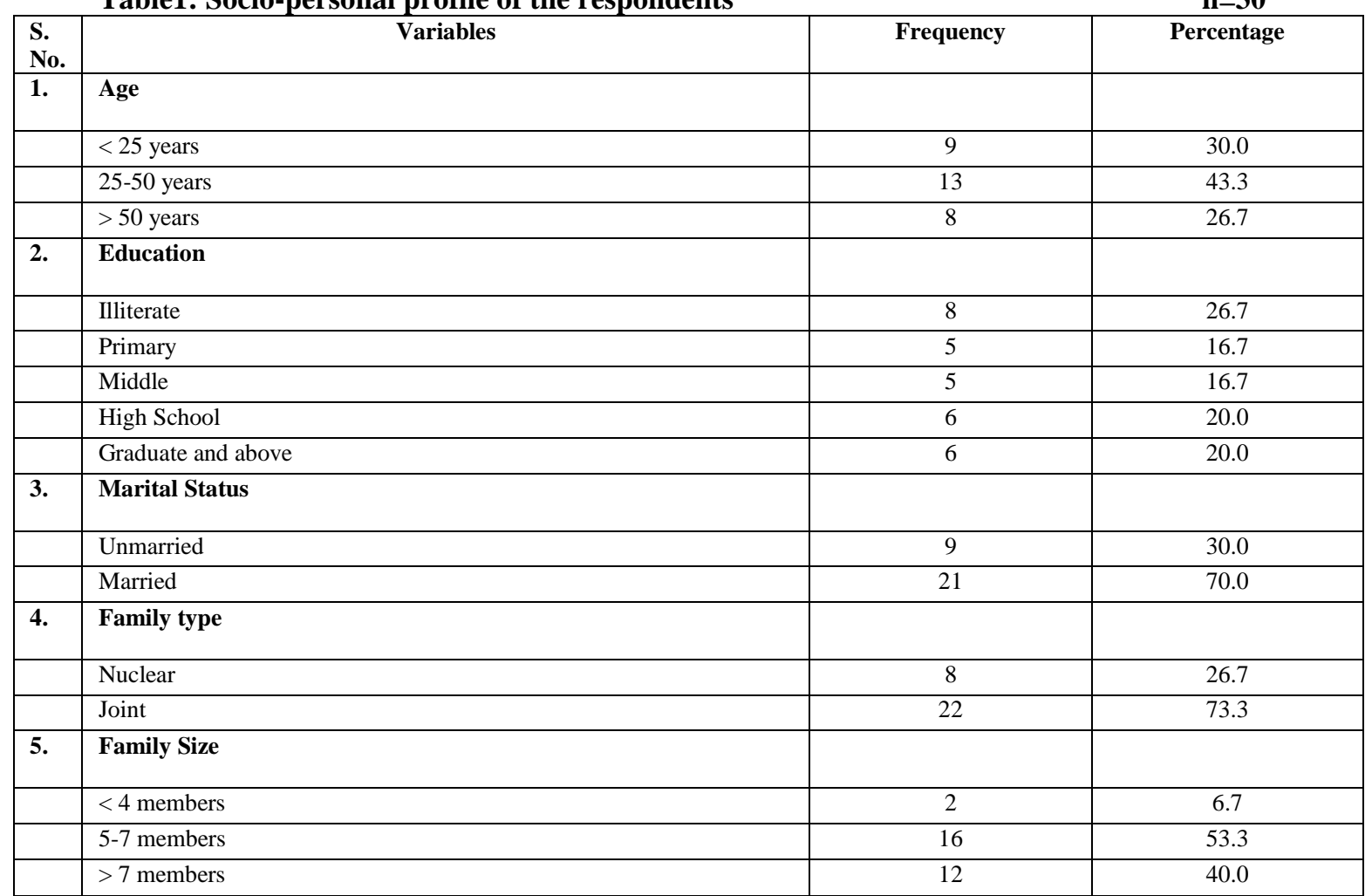

Table 2: Economic profile of the respondents

\begin{tabular}{|c|c|c|c|}
\hline \multirow{3}{*}{$\begin{array}{l}\text { S. No. } \\
1 .\end{array}$} & \multicolumn{2}{|l|}{ Iabl } & \multirow{2}{*}{$\frac{n=30}{\text { Percentage }}$} \\
\hline & Variables & Frequency & \\
\hline & Occupation of the respondents & & \\
\hline & Housewife & 18 & 60.0 \\
\hline & Service & 2 & 6.7 \\
\hline & Farming & 10 & 33.3 \\
\hline 2. & Family occupation & & \\
\hline & Service & 3 & 10.0 \\
\hline & Business & 4 & 13.3 \\
\hline & Farming & 23 & 76.7 \\
\hline 3. & Family monthly income & & \\
\hline & Low (Upto Rs10,000) & 8 & 26.7 \\
\hline & Middle (Rs 10,000-20,000) & 16 & 53.3 \\
\hline & High (Rs 20,000-30,000) & 6 & 20.0 \\
\hline 4. & Land holding & & \\
\hline
\end{tabular}




\begin{tabular}{|l|l|c|c|}
\hline & & & \\
\hline & $<5$ hectares & 4 & 13.3 \\
\hline & $5-10$ hectares & 18 & 60.0 \\
\hline & $>10$ hectares & 8 & 26.7 \\
\hline
\end{tabular}

Comparison of pre and post-exposure knowledge regarding rain water harvesting: It is evident from Table 3 that the pre-exposure scores regarding rainwater harvesting were found to be low. The maximum knowledge was regarding 'construction' and minimum for 'technical advantages' of rainwater harvesting. After imparting training, on critical look on gain in knowledge it is evident that the gain in knowledge was maximum for 'working' $(100.0 \%)$ followed by precautions $(96.0 \%)$, maintenance $(88.0 \%)$ and construction $(72.5 \%)$ respectively for rainwater harvesting. The ' $t$ ' value further indicate significant gain in knowledge and it was found in all the aspects.

Table 3: Comparison of pre and post-exposure knowledge regarding rain water harvesting

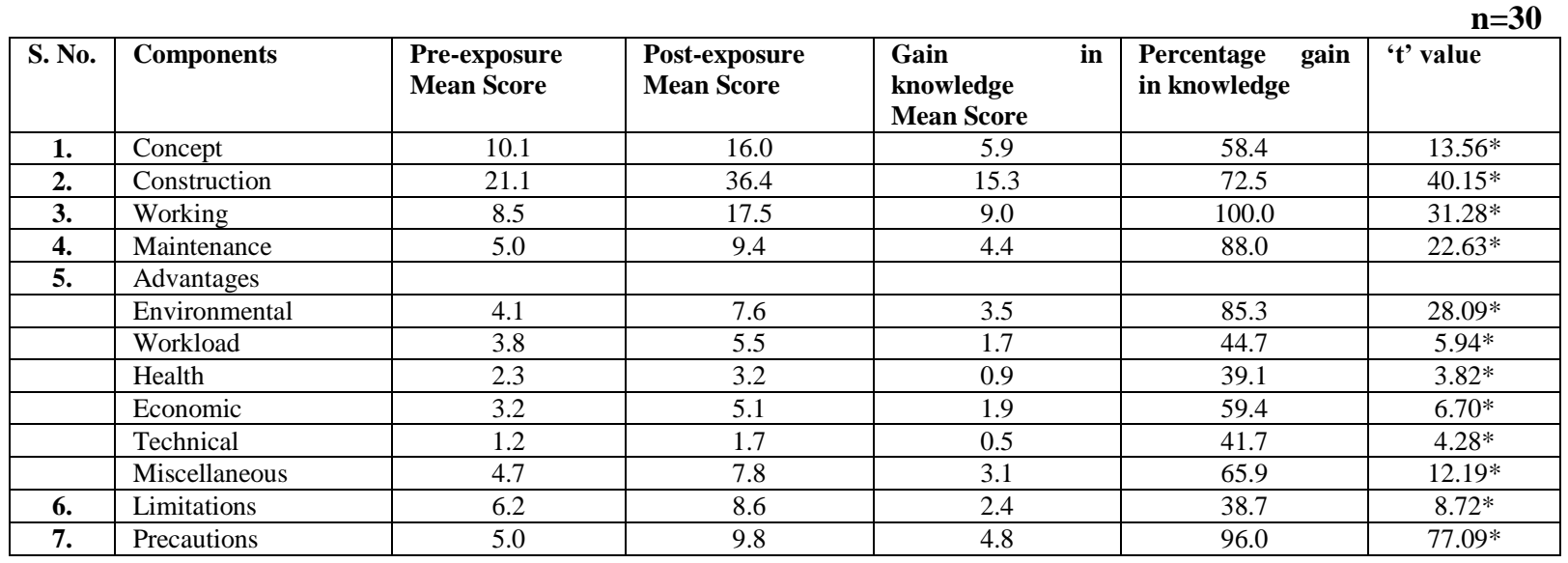

*Significant at $5 \%$ level of significance

This may be inferred from these findings that although respondents were aware to some extent about rainwater harvesting but they may or may not adopted the technology thus, through training they gained knowledge and sensitized to adopt the technology at their home and in farm by knowing its importance.

\section{Conclusion And Recommendations}

The technology of rainwater storage and harvesting is receiving attention as a new countermeasure for adaptive urban rainwater management under the crisis for climate change. Considering the domestic and irrigation purpose of miscellaneous water use, government is now providing fifty percent subsidy on construction of rainwater storage tank. The major motivational reasons for attending training were usefulness of training, water scarcity and to learn the new technology. Overall, gain in knowledge regarding rainwater harvesting was found to be high. Majority of the respondents were now ready to adopt the technology in their farm as well as in their homes as they were going through water stressed condition.

The awareness about the potential and common benefits of rainwater harvesting (RWH) has to be increased among men and women. It is essential for administrators and engineers to provide the scientific and quantitative information for citizens so that the introduction of rainwater storage and harvesting system could be promoted. Rain Water Harvesting needs to be implemented due to paucity of water resources. Nature has showered enough potential to recharge our existing water bodies and also to store water for years to come and to meet the present / future demands. Let us pledge today and start conserving water so that our next generation could not starve and fight for water. If we succeed in water conservation, there would be no world war for water.

\section{References}

[1]. Kumar, M. D. 2009. Roof water harvesting for domestic water security: Who gains and who loses? Water International 29:1, 43-53.

[2]. Tripathi, A. K. and K. U. Pandey. 2005. Study of rainwater harvesting potential of Zura village of Kutch district of Gujarat. Journal of Human Ecology 18:1, 63-67.

[3]. Zerah., M Helene. 2000. Water - Unreliable Supply in Delhi, French Research Institute of India.

[4]. www.ccsindia.org/policy/enviro/studies/wp0076.pdf 